\title{
Minimum Night Flow Analysis and Application of the Fixed and Variable Area Discharges Model for Characterizing Leakage in the Gorino Ferrarese (FE-Italy) District ${ }^{\dagger}$
}

\author{
Irene Marzola *, Stefano Alvisi and Marco Franchini \\ Department of Engineering, University of Ferrara, 44122 Ferrara, Italy; stefano.alvisi@unife.it (S.A.); \\ marco.franchini@unife.it (M.F.) \\ * Correspondence: irene.marzola@unife.it \\ + Presented at the 4th EWaS International Conference: Valuing the Water, Carbon, Ecological Footprints of \\ Human Activities, Online, 24-27 June 2020.
}

Published: 9 August 2020

\begin{abstract}
Leakage in water distribution systems is an important issue and of major interest for water utilities. In this study, the Minimum Night Flow (MNF) method to quantify the amount of water lost and the equations representing the relationship between pressure and leakage in power and FAVAD (Fixed and Variable Area Discharge) forms were applied to a District Metered Area (DMA) located in Gorino Ferrarese (FE, Italy) equipped with smart meters. The analysis carried out by exploiting the collected time series of user water consumption, DMA inflow, and pressure highlighted that: (a) the MNF method can lead to significant inaccuracy in leakage estimation in the presence of users with irregular consumptions, when based on literature values, and (b) the estimation of the parameters of the power and FAVAD equation is highly affected by the number and types of observed data used.
\end{abstract}

Keywords: water losses; Minimum Night Flow; FAVAD equation; power equation

\section{Introduction}

A leakage can be defined as the water loss from supply and distribution networks, which escapes beyond a controlled action [1]. The amount of water lost from pipe network in the world varies between $15 \%$ and $50 \%$ of the system input [2]. Leaky pipes can cause pressure insufficiency, increasing risk on water quality by allowing the intrusion of pollutants, and increasing the pumping cost as more energy is necessary [3]. Thus, evaluation of leakage levels (i.e., quantification of the amount of water lost), their characterization, and their relationship with pressure are a priority for water utilities.

For the evaluation of leakage level, different methods have been proposed in literature. Quite a common approach used by water utilities is the water balance. In this case the water volume lost is computed as the difference between the total input volume and the volume consumed by users in a certain time frame. Clearly, the accuracy of the leakage level estimation depends on the quality of the data available [4]. In fact, the water utility usually collects the time series of water inflow in the network, but as regards the consumed water volume, only the meter readings collected for billing purposes every $4 / 6$ months are generally available. This allows for an evaluation of the leakage level only in the very long-term.

To obtain a better evaluation of the leakage, or in the absence of water consumption data, the Minimum Night Flow (MNF) method can be applied. According to this method, the leakage level is 
estimated by subtracting from the minimum District Metered Area (DMA) inflow, usually occurring at night-time between 2:00 and 4:00 a.m. [5], which is reasonable user night consumptions. The nighttime is advantageous because during these hours the consumptions are generally quite small due to the limited user activities and the leakage flow rate represents a significant part of the total DMA inflow. Clearly, in this case the accuracy of the leakage level estimation depends on the accuracy of the user night consumption estimation, and to this end different values are suggested in literature, depending on the place in which they were estimated, such as, for example, $1.7 \mathrm{~L} / \mathrm{h}$ per household in UK [4] and $3 \mathrm{~L} / \mathrm{h}$ per property in Canada [6]. It should be considered that these values do not take into account possible irregular water usage.

Regarding the characterization of the leakage, that is its relationships with pressure, one of the most used equations also adopted by the International Water Association (IWA) is the power equation [7-9]:

$$
Q=C h^{N 1}
$$

where $Q$ is the leakage flow rate, $h$ the pressure head, $C$ the leakage coefficient, and $N 1$ the leakage exponent. Scientific literature shows that the power factor N1 can vary between values of about 0.5 and values even greater than 2, depending on the type of leak and pipe material behaviour [10-12]. However, making the exponent of the leakage equation a variable severs it from its fluid mechanics foundations and turns it into a purely empirical equation [13].

Another relationship provided in literature is the FAVAD (Fixed and Variable Area Discharge) equation [14]:

$$
Q=C_{q}(2 g)^{0.5}\left(A 0 h^{0.5}+m h^{1.5}\right)
$$

where $Q$ is the leakage flow rate, $h$ the pressure head, $g$ the acceleration due to gravity, $C_{q}$ flow coefficient usually equal to $0.65, A_{0}$ is the initial area at zero head differential, and $m$ the head-area slope. This model is based on the linear relationship between pressure and leak area for elastic pipe materials, confirmed from experimental study combined with Finite Element analysis [15-17].

This study shows the result of the application of the water balance and MNF methods for leakage assessment and power and FAVAD equations for leakage characterization to a DMA located in Gorino Ferrarese (FE) in Italy, for which the time series of water consumption for every user and the time series of inflow and pressure at the entry of the DMA were collected with specific time scales for a time frame of 45 days, highlighting the pros and cons of these methods.

\section{Materials and Methods}

The water distribution system considered serves the town of Gorino Ferrarese, in the province of Ferrara in northern Italy (Figure 1). The system is a natural DMA with only one water inflow point, and it supplies 294 users, 17 of which are commercial or not domestic.

The system is fed by a pumping station located nearly $6 \mathrm{~km}$ upstream of the DMA and equipped with variable speed pumps that are controlled in order to keep a pressure of about $30 \mathrm{~m}$ immediately downstream the pumping station itself during the day. The pressure control value is reduced for about $10 \mathrm{~m}$ during the night, from 11:00 p.m. to 7 a.m. (see Figure 2).

In spring 2016 the traditional smart meters were replaced with electromagnetic smart meters provided with data loggers that could record the value of the cumulative consumed volume with a sensibility of $1 \mathrm{~L}$ and a time steps variable from $1 \mathrm{~min}$ up to $1 \mathrm{~h}$.

In summer 2016 a measurement campaign was performed collecting the time series of (a) the water consumption of each of the 294 users, (b) the DMA inflow, and (c) the pressure at the DMA inlet point at a 5 min time step.

The time series of DMA inflow and water consumption of all the users was used to estimate the DMA leakage level by applying the water balance method. Indeed, by comparing the inflow time series with the time series obtained by summing up all the users' consumption time series it was possible to accurately compute the trend of the leakage of the DMA at a $5 \mathrm{~min}$ time step, resulting in a leakage flow around $0.4 \mathrm{~L} / \mathrm{s}$. Figure 3 a shows the DMA inflow (red line) and the sum of all the water 
use (blue line) for one day, for the sake of an example, whereas Figure $3 b$ shows the computed leakage over the entire monitoring period.

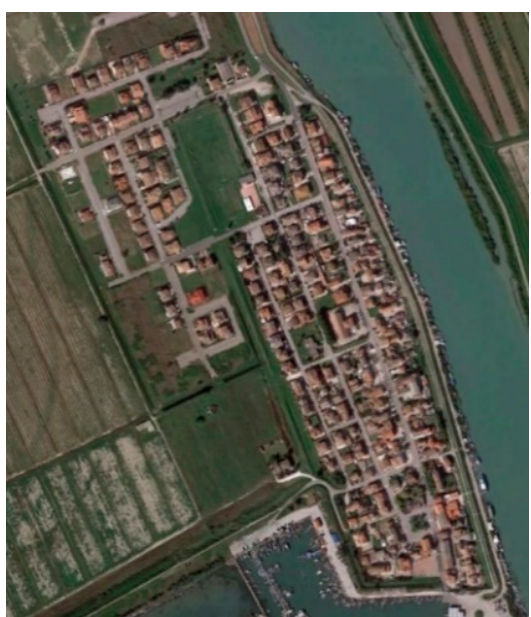

(a)

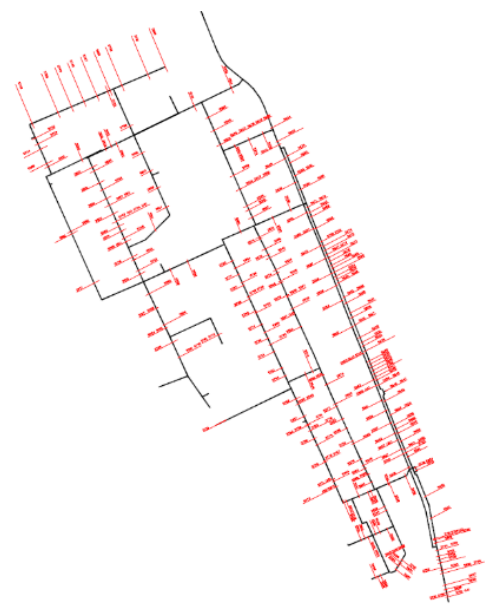

(b)

Figure 1. (a) Satellite view and (b) network layout and user connections of the district metered area of Gorino Ferrarese (FE-Italy).

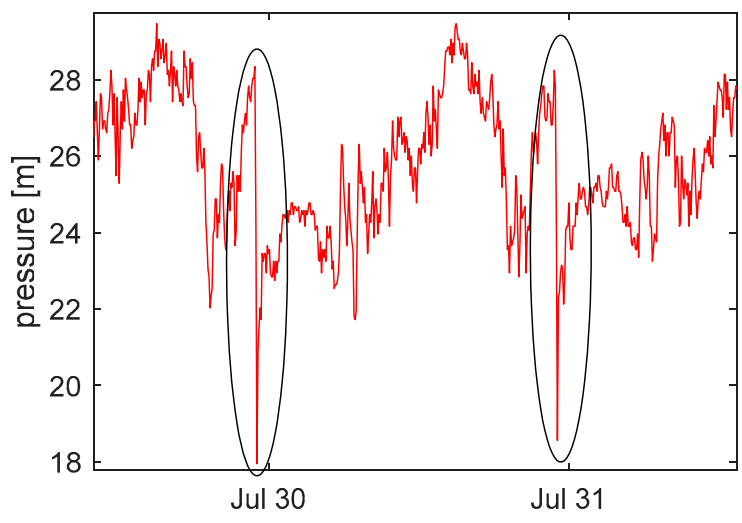

Figure 2. Trend of pressure at a 5 min time step over two days highlighting the operation of pressure reduction through two ellipses.

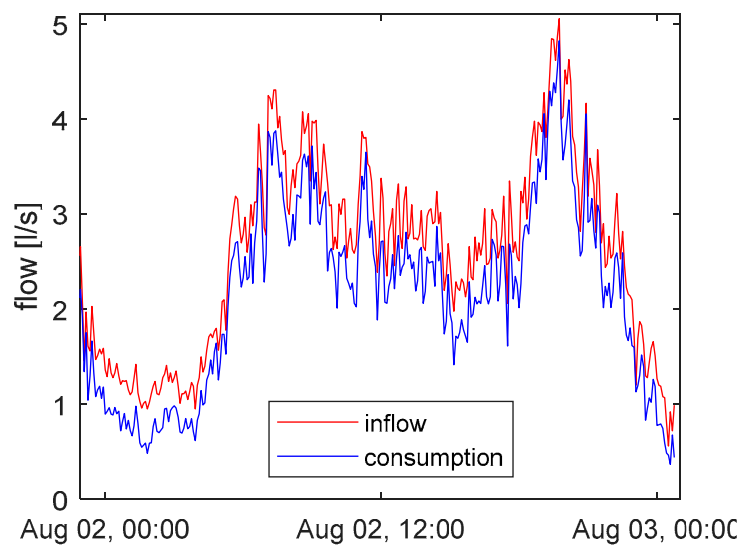

(a)

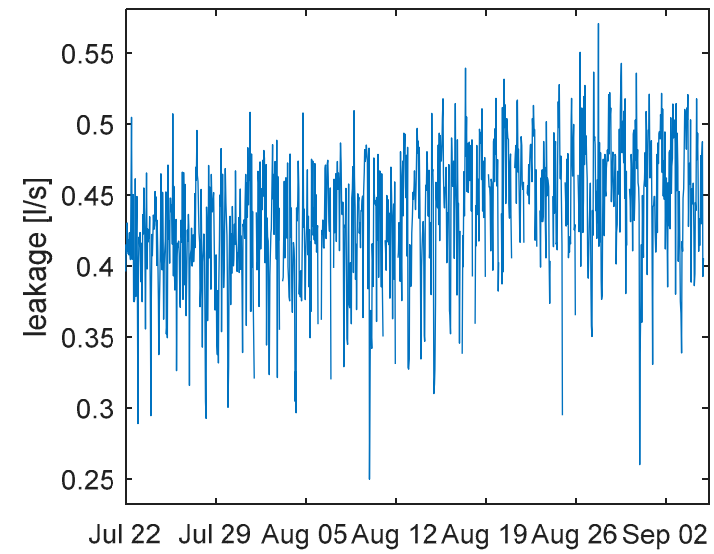

(b)

Figure 3. (a) District Metered Area (DMA) inflow (in red) and sum of all the user water consumption (in blue) at a 5 min time step over one day; (b) Trend of the leakage at a 60 min time step over the period of 45 days. 
The leakage rate estimated through the water balance was thus assumed as a reference leakage value and used (a) to evaluate the reliability of the MNF method for the assessment of the leakage level and (b) to evaluate the accuracy of different approaches for the parametrization of the power and FAVAD equations.

In more detail, with regard to the MNF, the analysis was carried out by extrapolating from the time series of user water consumption the minimum values (evaluated as the minimum flow registered for each user between 2:00 and 4:00 a.m. of each monitored day) and averaging these values considering (1) clusters composed of different numbers of residential users (from 5 up to 212 users) without home leakages or irregular consumptions, (2) all the previous users adding two users featuring nightly irrigation of $6 \mathrm{~L} / \mathrm{min}$ each, and (3) all the 294 users of the DMA including commercial ones. These sets will be indicated hereinafter respectively as set 1 , set 2 and set 3 .

The real values of minimum consumption of these sets were compared with corresponding ones provided in the literature, equal to $1.7 \mathrm{~L} / \mathrm{h}$ (UK) [4], $3 \mathrm{~L} / \mathrm{h}$ (Canada), $5 \mathrm{~L} / \mathrm{h}$ (Malaysia) per property, and of 0.4 and $0.8 \mathrm{~L} / \mathrm{h}$ per person, (respectively, in Germany and Austria) [6] for residential users while for commercial customers different values were used according to the types of activities as suggested by [4] or considering a general value of $8 \mathrm{~L} / \mathrm{h}$ as suggested in [6].

Regarding the relationship between leakage and pressure, the coefficients of the power and FAVAD equations were estimated using different methods. These coefficients are in fact generally estimated by using a couple of values of pressure and corresponding leakages observed before and after a marked pressure variation. Having at our disposal pressure and corresponding leakages values observed before and after the pressure reduction maneuverer done every day at 11 p.m. for a period of 45 days, in a first method the coefficients (i.e., exponent $N 1$ of the power equations, see Equation (1) and the head-area slope $m$ of the FAVAD equation, see Equation (2)) were estimated 45 times by using each time the couples of pressure and leakage values observed in a specific day. In a second method the 45 couples of pressure and leakage values were first averaged and then the two mean values used to estimate the coefficients. Thirdly, the method of the least squares was applied with all couples.

For this specific case study, however, the continuous time series of DMA leakage, that is generally not at water utility disposal, and the corresponding pressure at the DMA inlet point was also available. Therefore, as the fourth and fifth method to estimate the coefficients, the method of the least squares was applied considering all the leakages and pressure values observed throughout the 45 days, or all the values observed during night time, from 10:00 p.m. until 5:00 a.m. All these five methods, which will be indicated hereinafter, respectively, as $\mathrm{m} 1, \mathrm{~m} 2, \mathrm{~m} 3, \mathrm{~m} 4$, and $\mathrm{m} 5$, were carried out several times considering data at different time step, i.e., 5, 10, 15, 30, and $60 \mathrm{~min}$, and the coefficients estimated with each method and each time step were compared each other.

\section{Analysis of Results}

With reference to the results of the estimation of the MNF value, in Figure 4a the small black empty dots represent the minimum night consumption observed in each of the 45 monitoring days for each cluster composed of a different number of standard residential users (i.e., set 1, users without leakages within the house or night irrigation). For each cluster the mean value over the 45 days is plotted with a bigger black full dot. As expected, the average MNF increases with the number of users as highlighted by the least square interpolating straight line. In particular, considering the largest cluster, i.e., the cluster featuring all the 212 residential users without leakages within the house or night irrigation, it is worth noting that both the values observed in each day (black empty dots) and their mean value (black full dot) are well represented by the values that would be obtained for 212 users by considering most of the MNF values provided in the scientific literature plotted as green dots in Figure 4a. Indeed, a quite larger value would be obtained only considering the MNF value provided in scientific literature for Malaysian users [6].

However, considering set two, that is by including also two users with night irrigation, the minimum consumptions, plotted in yellow in Figure 4a, highly increase and their mean value (yellow full dot) exceeds even the one provided in literature for Malaysia. 
Finally, in Figure $4 \mathrm{~b}$ the values of the minimum consumption of all the users of the DMA, i.e., data set three, and the corresponding values of DMA inflow for the same hours and days are plotted in magenta and blue, respectively. Clearly, considering their mean values, that is the blue and magenta full dots, their difference represents the DMA leakage that in fact is around $24 \mathrm{~L} / \mathrm{min}$ (or 0.4 $\mathrm{L} / \mathrm{s}$ ) as estimated with the water balance. However, it is worth noting that if user water consumptions are not at the water utility's disposal, in the application of the MNF method done by subtracting from the minimum inflow (the blue full dot) the user night consumptions estimated by using the values provided in literature, here plotted in green, a significant overestimation of the leakage would be obtained. In fact, the estimated leakage would be three times the actual one, and this is mainly due to some residential users with home leakage and to some not residential activities whose night consumption is very difficult to estimate, such as a football field with a water night use of around 20 $\mathrm{L} / \mathrm{min}$ probably due to irrigation. Thus, at least for the case study considered, it results that MNF method would lead to an accurate leakage level estimation in presence of only residential users not affected by anomalies such as home leakages or night irrigation, whereas the presence of even a few users with anomalies or not residential users leads to a very inaccurate leakage estimation, if disregarded.

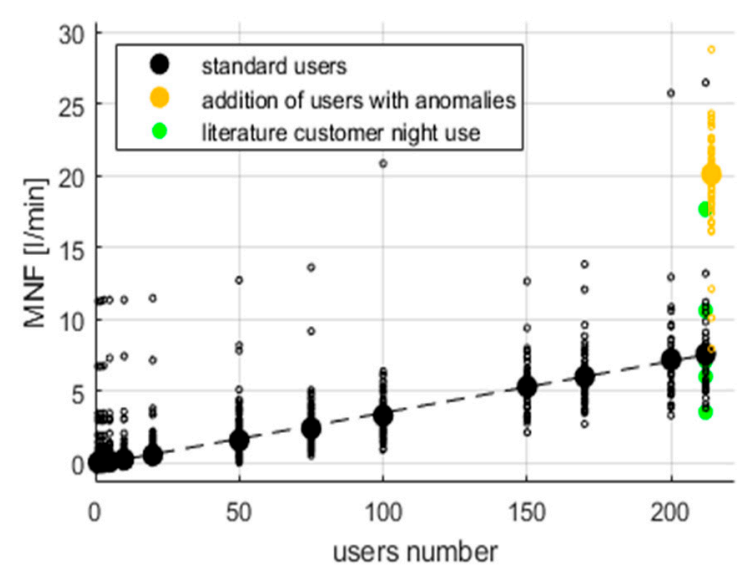

(a)

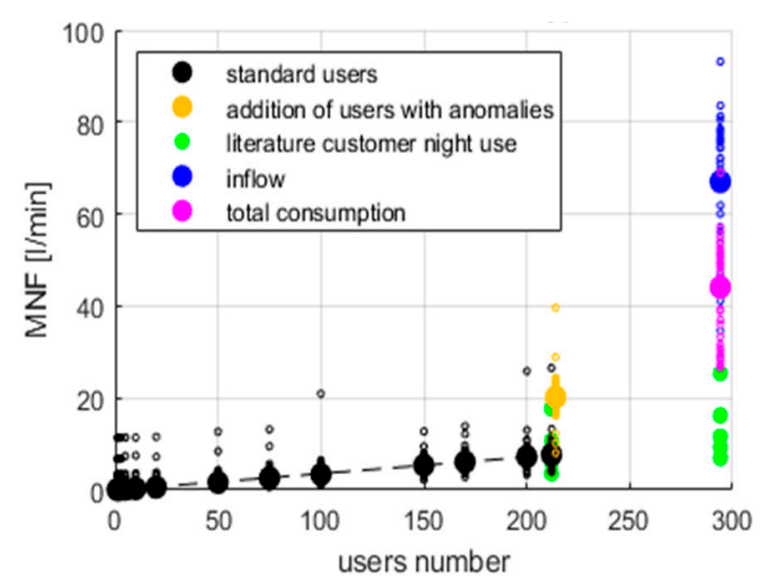

(b)

Figure 4. (a) Night consumption from set 1 (black empty dot) in L/min and their mean value (black full dot) fitted by a straight line, and values from set two (yellow empty dot) and their mean value (yellow full dot), compared with literature values (green dot). (b) Addition of minimum inflow (blue) and minimum total consumption (magenta) from set three.

Analysing the results regarding the characterization of leakage, in Figure 5 the values of coefficient $m$ of the FAVAD equation and of coefficient $N 1$ of the power equation estimated with the different methods above-mentioned are plotted as a function of the time step characterising the field pressure and leakage time series.

Considering the coefficient $m$ of the FAVAD equation it can be noticed that the 45 values resulting from method $\mathrm{m} 1$, that is by repeating the estimation 45 times using each time the couple of pressures and leakages observed in a different day before and after the evening pressure reduction, are extremely variable, particularly for quite short time steps, also with negative numbers that are without physical explanation. 


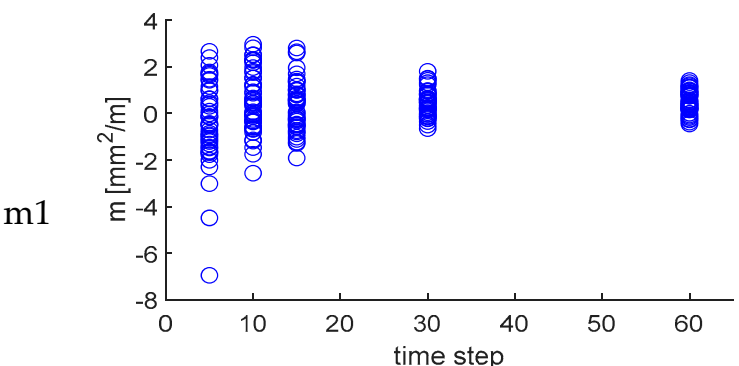

(a)

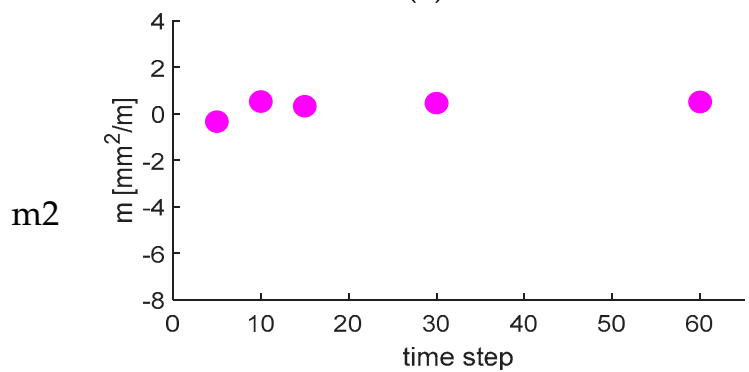

(b)

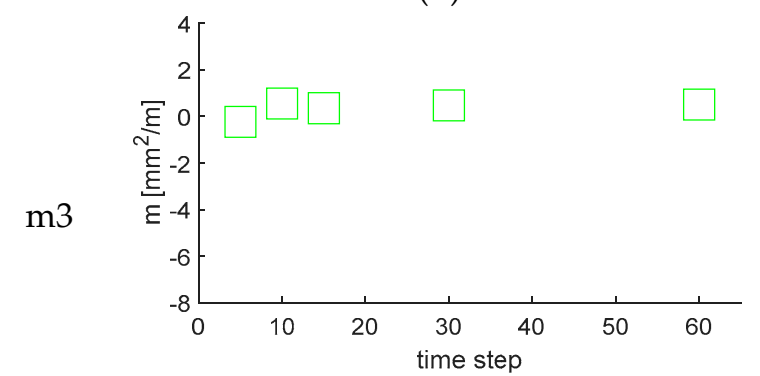

(c)

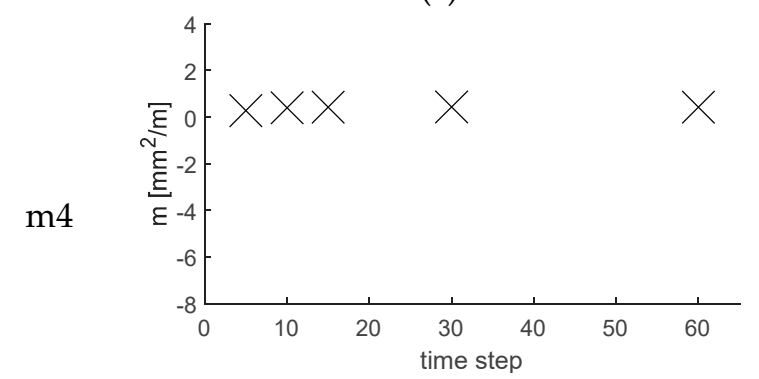

(d)

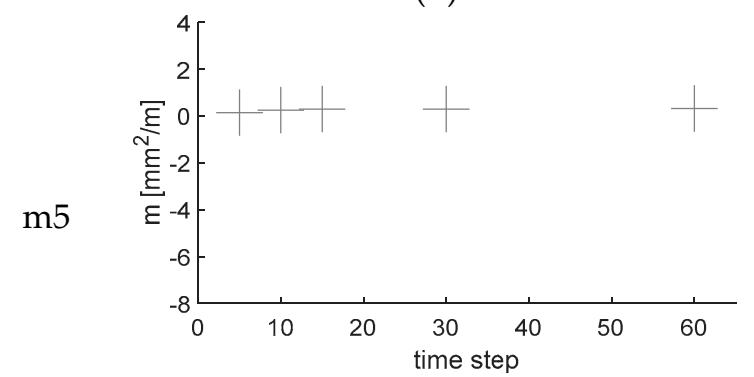

(e)

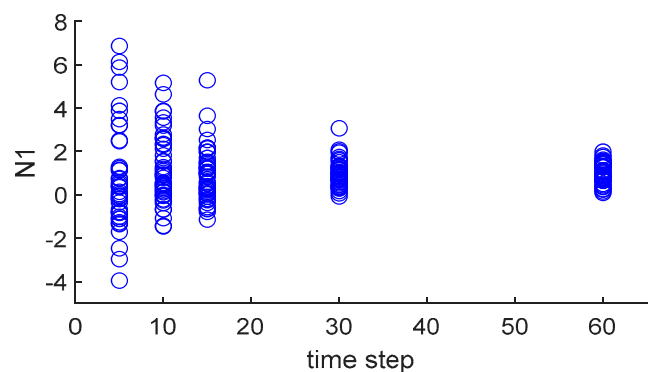

(f)

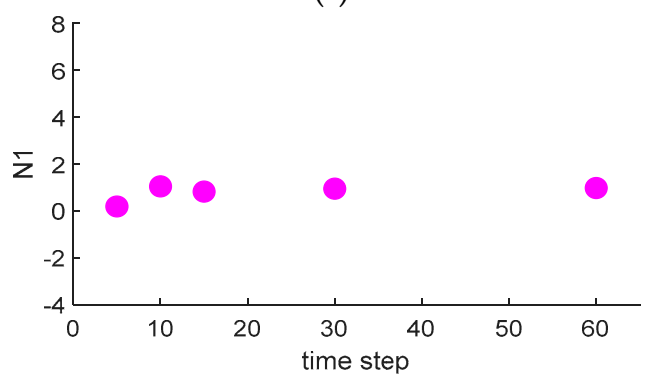

(g)

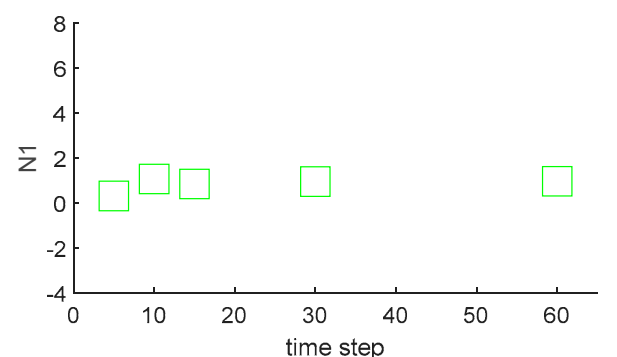

(h)

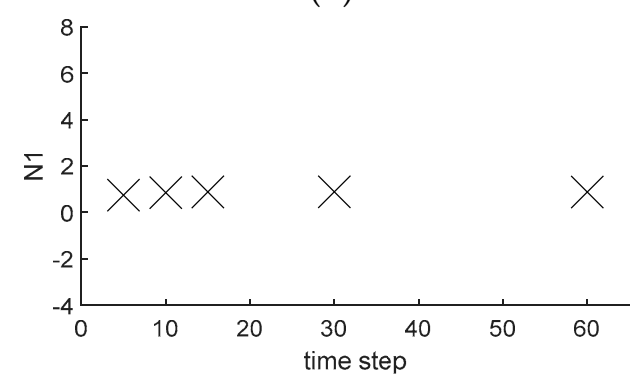

(i)

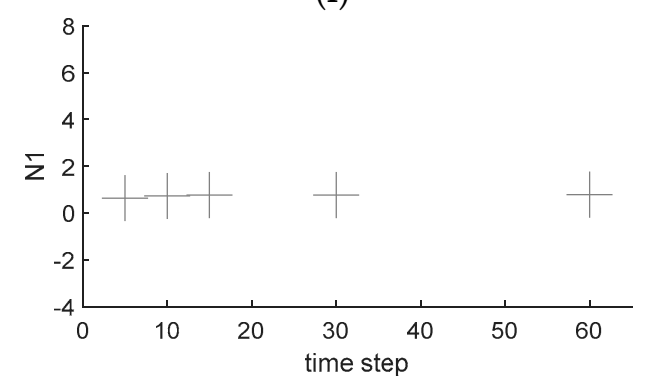

(j)

Figure 5. (a-e) Values of coefficient $m$ plotted as a function of the time step estimated with the different methods m1-m5. (f-j) Values of coefficient N1 plotted as a function of the time step estimated with the same methods.

The coefficients estimated with methods $\mathrm{m} 2$ and $\mathrm{m} 3$, i.e., using the averaged couple and the least square method with all couples, vary in a smaller range but still negative values can be observed when short time steps are considered. Therefore, considering only couples of data obtained by monitoring the pressure and leakage before and after a manoeuvre can lead to quite inaccurate 
results. On the contrary, methods $\mathrm{m} 4$ and $\mathrm{m} 5$, that is considering a large amount of data observed throughout the entire day or only in night hours, lead to coefficients whose values are independent from the time step considered and more physically sound. Similar considerations also apply for the exponent $N 1$ of the power equation.

The benefits of considering whole time series of pressure and corresponding leakages rather than one (or several) couples of data observed only before and after a manoeuvre is highlighted in Figure 6 where the FAVAD equations with coefficients estimated by using the different methods are plotted. As it can be observed, FAVAD equations whose parameters are estimated by using only couples of data can lead to quite unreliable estimation of the effects of the pressure variation on leakage, whereas FAVAD equations whose parameters are estimated by using the whole time series of pressure and leakages lead to a more reliable estimation.

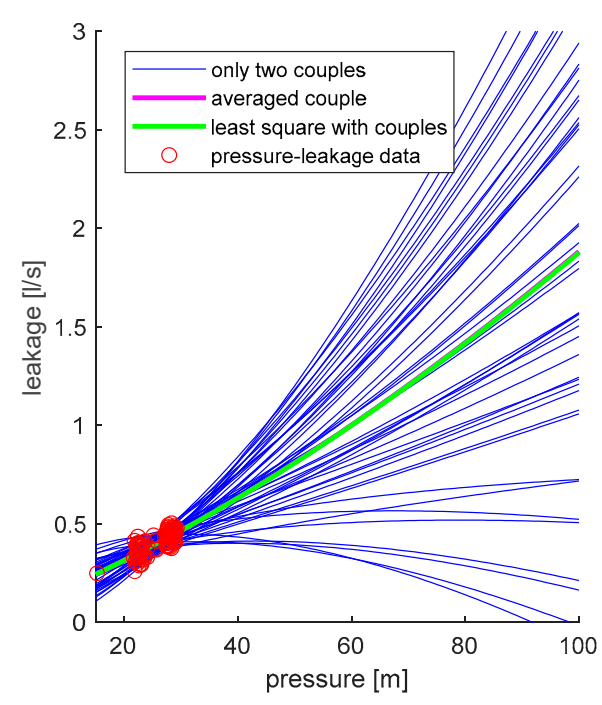

(a)

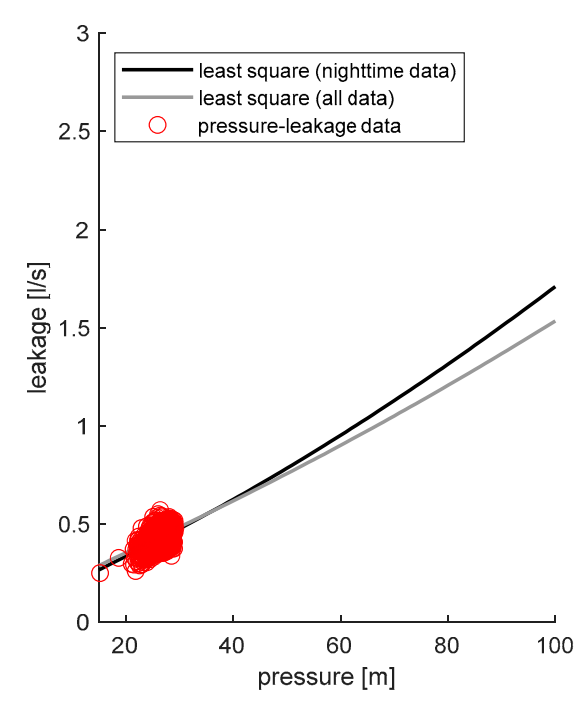

(b)

Figure 6. FAVAD equations with coefficient evaluated with data at a $60 \mathrm{~min}$ time step (a) from $\mathrm{m} 1 \mathrm{in}$ blue, from $\mathrm{m} 2$ in magenta and $\mathrm{m} 3$ in green and (b) from $\mathrm{m} 4$ and $\mathrm{m} 5$, respectively, in black and grey.

\section{Conclusions}

In this study results of leakage characterization in a fully monitored district evaluating both the amount of water loss by using the water balance method and the MNF method and the relationship with pressure by using the power and FAVAD equation have been presented.

The application of the water balance done by exploiting both the DMA inlet time series and the time series of water consumption of all the users of the district provided an accurate estimation of the leakage level. Considering the application of the MNF method, it was observed that the literature value of users' night consumption can lead to a wrong leakage estimation. Indeed, presence within the district of just few users with quite "irregular" night water use can cause a significant overestimation of the leakage level.

Regarding the parametrization of the FAVAD and power equation, different methods were applied to estimate the coefficients. It was observed that the use of only two couples of points obtained from pressure variation, as generally done in practice by several water utilities, can lead to unreliable results. The least squares method applied to entire time series of pressure and corresponding leakages is trustworthy, even though it is worth highlighting that this information, and in particular leakage time series, can be difficult to obtain and generally not at the water utility's disposal.

Author Contributions: Conceptualization, S.A. and M.F.; methodology, I.M., S.A., M.F.; software, I.M.; writing - review and editing, I.M., S.A. and M.F. All authors have read and agree to the published version of the manuscript. 
Funding: This research received no external funding.

Conflicts of Interest: The authors declare no conflict of interest.

\section{References}

1. Ofwat, the Economic Regulator of the Water Sector in England and Wales. 2019. Available online: https://www.ofwat.gov.uk/wp-content/uploads/2018/03/Reporting-guidance-leakage.pdf (accessed on 20 December 2019).

2. Kingdom, B.; Liemberger, R.; Marin, P. The Challenge of Reducing Non-revenue (NRW) Water in Developing Countries. How the Private Sector Can Help: A look at Performance-Based Service Contracting; the World Bank: Washington, DC, USA, 2006.

3. Colombo, A.F.; Karney, B.W. Energy and costs of leaky pipes: Toward comprehensive picture. J. Water Res. Plan. Man. 2002, 128, 441-450.

4. Butler, D. Leakage Detection and Management; Palmer Environmental: Cwmbran, UK, 2009.

5. Liemberger, R.; Farley, M. Developing a non-revenue water reduction strategy: Investigating and assessing water losses. In Proceedings of the IWA 4th World Water Congress, Marrakech, Morocco, 19-24 September 2004.

6. Fantozzi, M.; Lambert, A.O. Residential night consumption-Assessment, Choice of Scaling Units and Calculation of Variability. In Proceedings of the IWA Water Loss Conference, Manila, Philippines, 26-29 February 2012.

7. Lambert, A.O. International Report: Water losses management and techniques. Water Sci. Tech. Water Supply 2002, 2, 1-20.

8. Thornton, J. Managing leakage by managing pressure: A practical approach. Water 21 Mag. 2003, 3, 43-44.

9. Lambert, A.O. What do we know about pressure: Leakage relationships in distribution systems? In Proceedings of the IWA Conference on System Approach to Leakage Control and Water Distribution Systems Management, Brno, Czech Republic, 16-18 May 2001.

10. Farley, M.; Stuart, S. Losses in Water Distribution Networks; IWA Publishing: London, UK, 2003.

11. Greyvenstein, B.; van Zyl, J.E. An experimental investigation into the pressure-Leakage relationship of some failed water pipes. J. Water Supply Res. Technol. 2007, 56, 117-124.

12. Cassa, A.M; van Zyl, J.E.; Laubscher, R.F. A numerical investigation into the effect of pressure on holes and cracks in water supply pipes. Urban Water J. 2010, 7, 109-120.

13. van Zyl, J.E.; Malde, R. Evaluating the pressure-leakage behaviour of leaks in water pipes. J. Water Supply Res. Technol. 2017, 66, 287-299.

14. May, J. Leakage, Pressure and Control. In Proceedings of the BICS International Conference on Leakage Control Investigation in Underground Assets, London, UK, March 1994.

15. Ferrante, M. Experimental Investigation of the Effects of Pipe Material on the Leak Head-Discharge Relationship. J. Hydraul. Eng. 2012, 138, 736-743.

16. Ferrante, M.; Massari, C.; Brunone, B.; Meniconi, S. Leak behaviour in pressurized PVC pipes. Water Sci. Tech. Water Supply 2013, 13, 987-992.

17. Cassa, A.M.; van Zyl, J.E. Predicting the head-leakage slope of cracks in pipes subject to elastic deformations. J. Water Supply Res. Technol. 2013, 62, 214-223.

(C) 2020 by the authors. Licensee MDPI, Basel, Switzerland. This article is an open access article distributed under the terms and conditions of the Creative Commons Attribution (CC BY) license (http://creativecommons.org/licenses/by/4.0/). 